\title{
Food Consumption in the Context of Covid-19 Pandemic: Romanian Market Analysis
}

\author{
Roxana Procopie ${ }^{1}$, Magdalena Bobe ${ }^{2}$, Robert Bumbac ${ }^{3}$ and Smaranda Giușcă ${ }^{4}$ \\ 1)2334) The Bucharest University of Economic Studies, Bucharest, Romania. \\ E-mail: roxana.procopie@com.ase.ro; E-mail:magdalena.bobe@com.ase.ro; \\ E-mail: robert.bumbac@com.ase.ro; E-mail: smaranda.giusca@com.ase.ro;
}

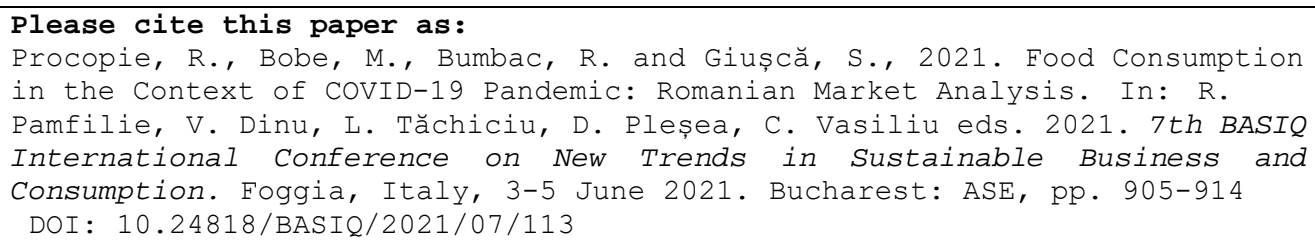

\begin{abstract}
The Covid-19 pandemic and the measures taken to reduce the virus spreading have left their mark on many sectors of activity, including the food industry. In order to better understand the main changes in eating behavior and to identify the factors that contributed to changing the eating habits in this atypical context generated by the pandemic, a secondary analysis of statistical data on food consumption in Romania was performed. The data taken into account were those available on the Euromonitor International platform as well as in other reports published on this topic. The analysis of the values registered in Romania in 2020, compared to the pre-pandemic period (2015-2019) and to the pandemic and post-pandemic estimation (2021-2025) highlighted the orientation of consumers towards essential foods, implicitly the increase of vegetable and meat consumption, and a decrease in the consumption of fruits, sugar and sweeteners. Moreover, the study shows a growing awareness of the importance of health and quality issues in food choice, of the increasing importance of home delivery in the purchasing decision, all in the context of a maintained price sensitivity. The possible practical implications draw our attention to agri-food businesses' need to adapt to current socioeconomic realities, in an attempt to understand the new purchasing behaviors and to meet the current food consumption requirements of the population.
\end{abstract}

\section{Keywords}

Food consumption, packaged food, fresh food, changes, estimates, Covid-19 pandemic, consumption behavior, Romanian market.

DOI: $10.24818 / B A S I Q / 2021 / 07 / 113$

\section{Introduction}

With its place between objectivity and subjectivity, eating behavior plays an essential part both in personal health as well as population health, given that current patterns of food production and consumption have a major impact on the food system and its sustainability (Janssen, et al., 2021).

Eating behavior is influenced by the level of culture, which is based in turn on the level of education and the capacity for analysis, systematization and interpretation of knowledge. While economic and utility considerations are the easiest to identify as having a part in guiding the eating behavior, traditions, beliefs, habits, fashion, attitudes and personal experiences also play an important part in guiding it. On the other hand, eating behavior can undergo significant changes under the impact of unforeseen situations, such as the case of the COVID-19 pandemic, which brought major changes in all sectors of activity including the food system (PricewaterhouseCoopers, 2021). 
In Romania, the pandemic impact on incomes, the labor market uncertainty, coupled with the psychological effects on consumers (e.g. cutting down on non-essential expenditures) and restricting the activity of the hospitality sector are factors that contributed to changing the buying and consumption behavior of the population in 2020 (Competition Council Romania, 2020). One can observe how the patterns of the Romanian consumer's behavior are more and more similar to those of consumers in developed countries such as Germany, Denmark, France or the USA. Specifically, the change in the pattern of consumption, also observed in the evolution of food sales, has been achieved in the sense of increasing demand for staple foods, especially non-perishable foods, and also an increase in demand for pharmaceuticals, amid movement restrictions and economic uncertainty. At the same time, more and more consumers have rediscovered the method of preparing food in the household (Sandi Wachyuni and Wiweka, 2020).

\section{Review of the scientific literature on changes in food behavior due to COVID-19 pandemic}

Culture reflects the distinct characteristics of a society in spiritual, material, intellectual and emotional terms (UNESCO, 2001), and the appreciation of cultural behavior involves the evaluation of both the activity in society and the way of eating. Eating behavior includes a series of innate reflex reactions (instincts), as well as reactions acquired during life through experience in response to internal or external stimuli that require food intake. Thus, eating behavior translates into performing certain physical acts, aiming at the intake of nutrients, in the form of food, whose meaning is much more complex than that of the nutrients they contain.

From a conjunctural point of view, the health crisis generated by Covid-19 caused unexpected changes, in a short time, in the behavior of food consumption, changes signaled by global and local studies and research. Consumer preferences of people around the world have changed. After the initial period of non-discriminatory food storage, observed in many countries following the introduction of restrictions, the impact of COVID-19 on the eating habits of the population varied according to individual and household attitudes and experiences (Borsellino, Kaliji and Schimmenti, 2020).

A change in eating-related buying behaviors is noticeable - studies (McKINSEY and Company, 2020) show that people around the world have tried different buying behaviors and expressed a high intention ( $65 \%$ or more) to maintain these behaviors in the future. However, in countries where the economic shock was less felt (Germany and Japan, for example), the change in purchasing behavior was less pronounced; a national study for three developed European countries - Denmark, Germany and Slovenia - (Janssen, et al., 2021) highlighted that these were caused by the lockdown and personal factors such as anxiety related to COVID-19, loss of income, household composition and gender. These results help identify populations that are particularly vulnerable to nutritional changes during the pandemic and the ways that might minimize the negative effects of the pandemic on food consumption.

More and more consumers are manifesting unhealthy eating behaviors. According to Simone, et al. (2021) the most common unhealthy eating behaviors, associated with lower stress control, greater depressive symptoms and moderate or extreme financial difficulties are: eating and snacking as a nervous reaction; increasing food consumption in general; decreased appetite and reduced food intake; eating to cope; increasing the number of eating disorder symptoms (Simone, et al., 2021).

Gradually, people gave up the initial stockpiling behavior. The COVID-19 pandemic caused blockages throughout the agri-food system, influencing food supply chains from primary production, processing, transportation, marketing to consumption. These demonstrated the resilience of the agri-food system, with stores constantly supplied and meeting the increased demand, so that the initial stockpiling behavior disappeared (OECD, 2020a). This trend manifested itself not only in European countries, but also in the United States, where, at the beginning of the pandemic, consumers tended to buy more food than usual, a trend that declined later (Chenarides, et al., 2021).

In what concerns the choice of new brands and of the place of purchase, consumers reconsidered the factors that influenced their decisions in certain respects. Consumer price sensitivity remains the main reason why they are trying new brands as well as new shopping places. In addition to price, convenience and availability are increasingly important factors in choosing the place of purchase, while the quality and the desire to support local companies are mentioned as the main drivers of consumer decision (McKINSEY and Company, 2020). 
Another trend specific to this period is the increase in the share of food consumed at home to the detriment of those consumed outside the home (in hotels, restaurants, catering and cafes). COVID-19 has led to a drastic decrease in consumer demand for food consumed in the hospitality network, which requires major changes in the way food supply chains operate (OpenTable, 2020). In Germany and Slovenia, $22 \%$ of the respondents in a study by Janssen et al. used to eat at cafes and restaurants at least once a week before the pandemic, which also meant a shift to online orders (Janssen, et al., 2021). At the same time, grocery stores have seen an average increase of over $30 \%$ in the online customer base in different countries (McKINSEY and Company, 2020) explained by the fact that consumers tried to avoid shopping at the beginning of the pandemic, when clear rules of protection (such as wearing masks, stickers for distance, etc.) did not yet exist (Chenarides, et al., 2021). Thus, online food orders - both nationally and by food category, have increased as consumers in most parts of the world spend more time at home. In Europe, the COVID-19 pandemic has drastically changed the way food is ordered online, as online delivery expands choice and availability, allowing consumers to order from more and more diverse locations through the use of more and more applications and delivery platforms. Thus, the value of the Europe Online Food Delivery market in 2020 was USD 13.8 Billion, and is estimated to reach the level of USD 20.27 billion by 2026 (Research and Markets, 2021b). Statistics show that revenues from the global online food delivery market increased from USD 107.44 billion in 2019 to USD 136.4 billion in 2020. The upward trend will continue in the coming years, with this value estimated to increase to USD 182.3 billion until 2024 (Research and Markets, 2021a; Business Wire, 2021).

Global research published by McKinsey and Company (2020) reveals that the impact of the pandemic is felt differently in different countries, despite the general uncertainty. In most countries, consumers redirect their spending towards the purchase of essential food and household products, to the detriment of discretionary spending such as travel and clothing (McKINSEY and Company, 2020). It can be said that the global spread of the SARS-CoV-2 virus marked the last period (2020-2021) from an economic and social point of view and strongly impacted both developed and emerging or developing economies.

\section{Research methodology}

In order to identify the main changes generated by the Covid-19 pandemic, an analysis of the secondary data identified in specialized reports was performed. Collected data was available from McKinsey and Company, Boston Consulting Group, PricewaterhouseCoopers, Ernst and Young, Competition Council, Research and Markets etc. as well as data provided by Euromonitor International. Specifically, the quantitative data on food consumption in Romania in the period 2015 - 2020 and the estimated data for the period 2021 - 2025 (published on the Euromonitor International Passport platform) were interpreted, making a comparison between the trends and values recorded until 2019 and those recorded after 2020.

The main focus were the differences between Packed Food vs. Fresh Food as well as the evolution of the main categories of Fresh Food products. Euromonitor International defines Packaged Food as packaged and prepared foods and includes both retail sales (all shops, excluding hotels, cafes, restaurants, canteens, etc.) and foodservice (restaurants, fast food, home-delivery, takeaway, cafe-bars, street kiosks etc.). At the same time, Fresh Food refers to all unprepared and unprocessed foods whether or not they are packaged (including packaged dried fruits or raw sugar), regardless of the distribution channel (including retail as well as Foodservice or institutions) as long as they are meant for home preparation and consumption. The total sales volume of these product categories is referred to as market size. The steps followed in conducting this research were: (1) identifying the main food changes identified internationally in the literature and the reports made by companies in the field; (2) extracting and analyzing relevant statistical data on food consumption in Romania; (3) understanding the factors that contributed to these changes; (4) identifying the main changes in food consumption in Romania and globally.

\section{Results and discussion}

In Romania, as in other European countries, not only the crisis but also the measures taken to limit the spread of the virus have left their mark on many sectors of activity and imposed interventions that have led to many changes in people's consumption preferences. From the analysis of the data regarding 
packaged vs fresh food (Figure no. 1) it can be seen that the year 2020, the year of the Covid-19 crisis, did not bring major changes regarding the growth trend of packaged and prepared foods. A possible interpretation in this sense could be that the losses registered by the decrease of the Foodservice sector were compensated by an increase of the quantity of products prepared in the Retail sales sector, people having to find alternatives for the consumption of ready-to-eat foods to eat at home or through the increased use of online platforms for home delivery of ready-to-eat food. The same cannot be said for fresh food, which has seen a significant increase in 2020 compared to future growth estimates. This phenomenon can be justified by the forced increase of food consumed at home to the detriment of food consumed away from home, as was the case before the pandemic. Other factors that have influenced this increase may be a greater concern for health and, in some cases, an increase in the time available for better planning, preparation and consumption of natural foods. Cooking at home has led to an increase in the consumption of staple foods largely included in the fresh food category. In Romania's case, the significantly higher share of the fresh food category compared to packaged food is also explained by the share of food products of 33\% of total consumer spending (compared to the European average of approx. 16\%), a situation that influences the structure of the consumption basket (Competition Council Romania, 2020).

As seen in Figure no. 1, the gap between Packaged and Fresh Food is expected to gradually narrow by 2025 , as this gap is expected to narrow and as activities and lifestyles will return to their period-specific normality before the Covid-19 crisis.

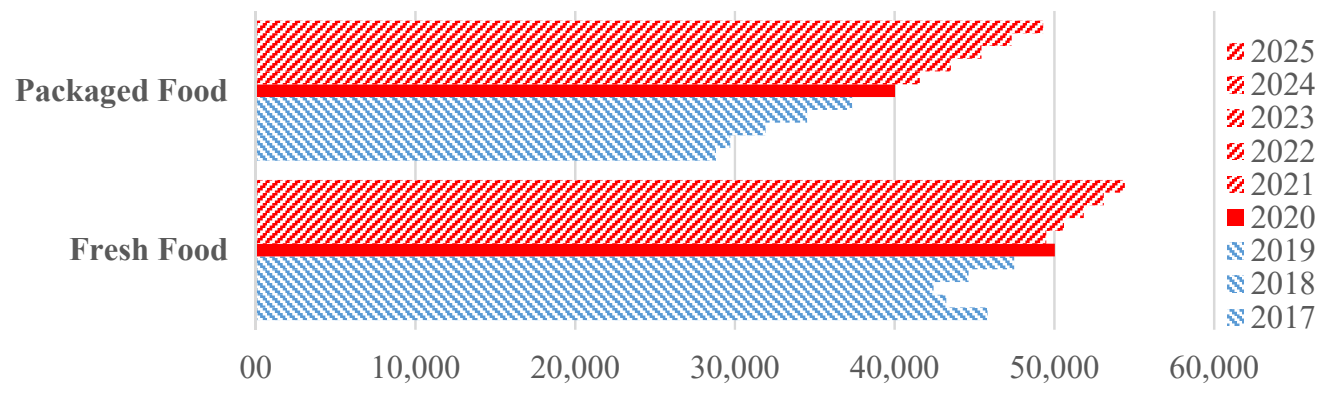

Figure no. 1. The Romanian Food Market Size before and after COVID-19 pandemic (Fresh Food vs Packaged Food, current prices RON million)

Source: Own representation based on data from Euromonitor International.

An increase in the volume of food purchases can be observed, and the increase is more accentuated in the case of fresh food products, with an obvious migration to local products to the detriment of imported ones, as shown by the study conducted in Romania by Ernst and Young (Carstoiu, 2020). To better understand the structure of the consumer basket and more precisely which are the types of products in the Fresh Food category that contributed to this increase in 2020, the changes registered for the main products were analyzed (as seen in Figure no. 2). Thus, it can be said that, in Romania, in the case of Fresh Food type foods, in the case of Fresh Food type foods, the Covid-19 pandemic led to:

- a change of trend (for the period 2020-2025 vs the period 2015-2019):

- in the negative in the case of starchy roots, sugar and sweeteners, fish and seafood;

- respectively in a positive sense for products in the vegetables and meat category;

- an annual increase (2020 vs. 2019) in the consumption of vegetables, meat, nuts (excluding from this category fried or peeled nuts, as well as those used for flavoring beverages and extraction of oil), pulses (especially dry beans, peas and other pulses);

- an annual decrease (2020 vs. 2019) in the consumption of starchy roots (such as potatoes, cassava and other roots), fruits, sugar and sweeteners (excluding those used for industrial processing), eggs, fish and seafood. 


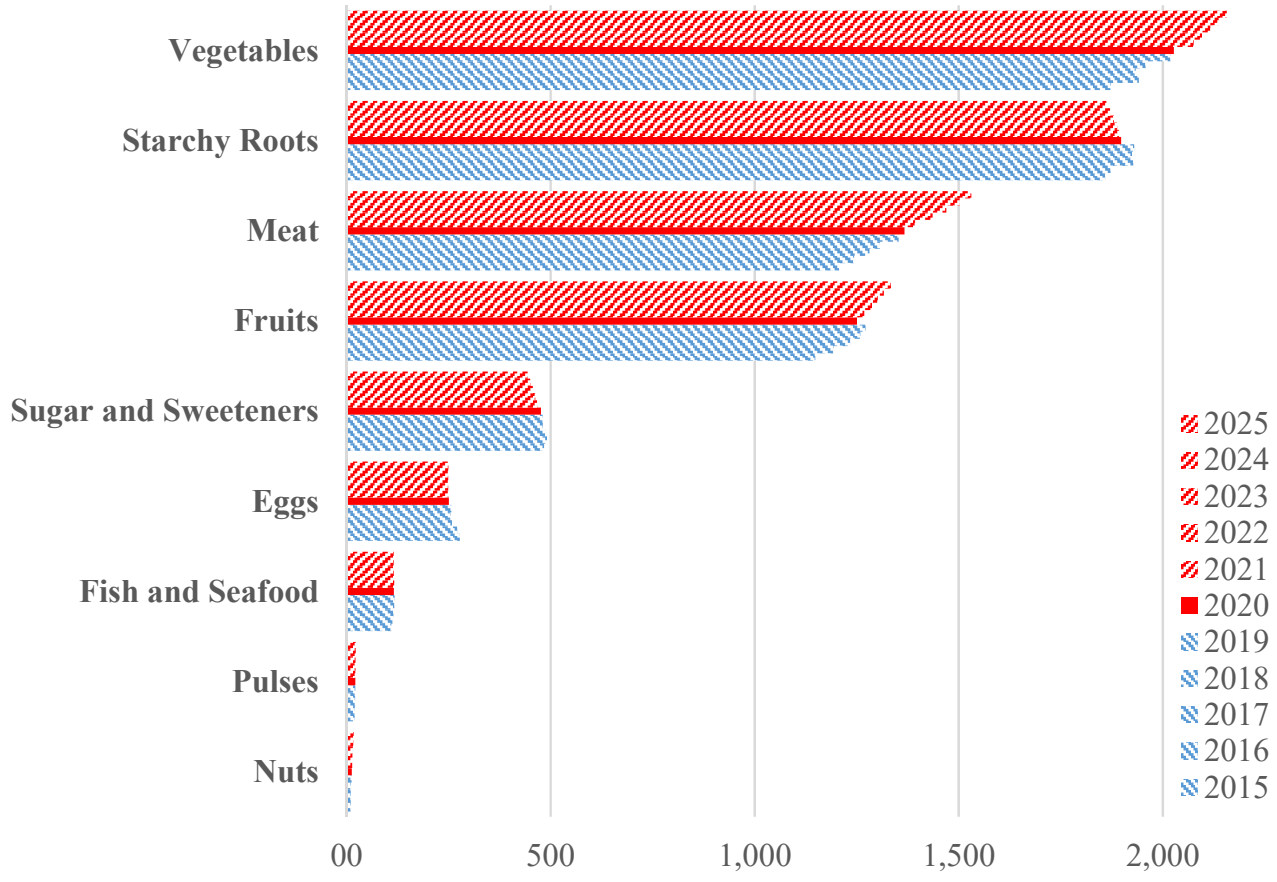

Figure no. 2. The Romanian Food Market Size before and after COVID-19 pandemic (main food categories, total volume in thousand tonnes)

Source: Own representation based on data from Euromonitor International.

These variations are also confirmed by the values recorded in Table no. 1, which provides a detailed perspective on the percentage changes in quantity consumed from one year to another. The use of different colors helps us understand whether the variation is an increase or decrease and its amplitude. One can easily identify the main changes that occurred in 2020, in terms of food consumption in Romania, compared to the previous year and the estimation of their variation for the next period, until 2025.

\begin{tabular}{|c|c|c|c|c|c|c|c|c|c|c|c|}
\hline Category & 2015 & 2016 & 2017 & 2018 & 2019 & 2020 & 2021 & 2022 & 2023 & 2024 & 2025 \\
\hline Eggs & $-1,10 \%$ & $-2,41 \%$ & $-4,68 \%$ & $-1,51 \%$ & $\begin{array}{r}0,75 \\
\%\end{array}$ & $-2,30 \%$ & $-0,64 \%$ & $-0,12 \%$ & $\begin{array}{r}0,00 \\
\%\end{array}$ & $\begin{array}{r}0,16 \\
\%\end{array}$ & $\begin{array}{r}0,28 \\
\%\end{array}$ \\
\hline $\begin{array}{l}\text { FishandSeafoo } \\
\text { d }\end{array}$ & $1,57 \%$ & $2,64 \%$ & $2,13 \%$ & $1,57 \%$ & $0,77 \%$ & $-1,53 \%$ & $0,52 \%$ & $-0,52 \%$ & $-0,35 \%$ & $-0,17 \%$ & $-0,09 \%$ \\
\hline Fruits & $-1,73 \%$ & $3,87 \%$ & $3,43 \%$ & $2,02 \%$ & $1,02 \%$ & $-1,67 \%$ & $1,46 \%$ & $1,46 \%$ & $1,11 \%$ & $1,15 \%$ & $1,32 \%$ \\
\hline Meat & $2,37 \%$ & $3,06 \%$ & $3,09 \%$ & $1,97 \%$ & $3,49 \%$ & $1,06 \%$ & $1,90 \%$ & $3,10 \%$ & $2,35 \%$ & $2,23 \%$ & $1,87 \%$ \\
\hline Nuts & $1,02 \%$ & $2,02 \%$ & $0,99 \%$ & $0,98 \%$ & $16,50 \%$ & $3,33 \%$ & $8,06 \%$ & $6,72 \%$ & $6,99 \%$ & $6,54 \%$ & $6,13 \%$ \\
\hline Pulses & $2,09 \%$ & $2,05 \%$ & $3,52 \%$ & $0,97 \%$ & $1,92 \%$ & $0,47 \%$ & $-0,94 \%$ & $1,42 \%$ & $0,93 \%$ & $1,39 \%$ & $1,37 \%$ \\
\hline Starchy Roots & $0,97 \%$ & $0,72 \%$ & $2,96 \%$ & $-0,16 \%$ & $0,30 \%$ & $-1,66 \%$ & $-0,28 \%$ & $-0,24 \%$ & $-0,44 \%$ & $-0,48 \%$ & $-0,51 \%$ \\
\hline $\begin{array}{l}\text { Sugar and } \\
\text { Sweeteners }\end{array}$ & $0,17 \%$ & $1,45 \%$ & $-0,88 \%$ & $-1,17 \%$ & $-0,06 \%$ & $-0,90 \%$ & $-1,89 \%$ & $-0,99 \%$ & $-1,34 \%$ & $-1,29 \%$ & $-1,31 \%$ \\
\hline Vegetables & $3,04 \%$ & $3,64 \%$ & $-0,38 \%$ & $1,23 \%$ & $3,12 \%$ & $0,43 \%$ & $2,39 \%$ & $0,98 \%$ & $0,98 \%$ & $0,95 \%$ & $0,95 \%$ \\
\hline
\end{tabular}

Among the series of changes noticed are:

- a significant increase in the consumption of nuts, a trend that continues since 2019, largely justified by a significant increase of investments and by a development of companies in this field of activity, implicitly of the food offer in this category;

- an increase in meat consumption, but this trend has been recorded before and continues after the Covid-19 pandemic, which can be explained as a general situation in developing countries; 
- the decrease in fruit consumption only in 2020 is an atypical change in the general variation of this indicator, possibly explained by the increase in consumption of frozen and canned vegetables as well as disruptions in the availability of certain categories of foods caused both by labor problems and by transportation problems - especially in the case of perishable products which generally have small stocks;

- a decrease in the consumption of sugar and sweeteners, which indicates a greater attention to the products consumed and the tendency of the population to focus on basic products and a reduction in the consumption of non-essential foods which include most of the products continuing sugar or sweeteners, a trend estimated to be maintained until 2025;

- a decrease in starchy roots mixed with a slight increase in vegetables, explained by an increased interest in fresh products with higher vitamin content.

These causes only partially explain the identified changes, as it is difficult to differentiate between consumption patterns within a category or even between different product categories, and the variance can be attributed to factors that cannot be easily identified or controlled.

\section{Understanding the factors that contributed to about reshaped consumer food behavior: factors related to Covid-19}

With its rapid evolution, the medical crisis caused by Covid-19 brought many changes in people's lifestyle. The perceived level of risk and anxiety generated by the pandemic had significant effects on food consumption (Janssen et al., 2021). A study by PricewaterhouseCoopers suggests that some of these changes will have long-term effects on consumers' purchasing behavior (PricewaterhouseCoopers, 2021).

Financial, economic and logistical constraints have become relevant in understanding the influence of the coronavirus pandemic on food purchasing and consumption behavior in general (Borsellino, Kaliji and Schimmenti, 2020). Modeling the eating behavior is thus the result of combining known factors related to the individual and the environment - with unpredictable factors, such as the Covid-19 pandemic. Individual factors and personal differences, such as a greater emphasis on health or convenience, are always in competition with the body's requirements for nutrients. In turn, individual factors are more influenced by environmental factors (which are given increasing importance today taking into account the consumers' quality of life and their ability to adapt) than by the ability to fulfill the physiological and metabolic needs. Moreover, environmental factors influence nutritional behavior through effects on food production and availability.

According to the analysis made in the previous chapter, most of the changes identified were caused by contextual factors, of an objective and subjective nature, being generated by conditions and circumstances which, at one point in time, influence the eating behavior. More interesting to note is the fact that this type of factors has the ability to reshape consumer behavior in the medium and long term, such as:

- lower accessibility to food - the Covid-19 pandemic both influenced the agri-food system, which proved to be resilient, and lead to a decrease in the income of many socio-professional categories. Thus, the main risk to food security is not necessarily related to the availability of food but also to the convenience and the consumers purchasing power. A number of precise and flexible social policies are essential in this regard in order to avoid increasing hunger and food insecurity, especially in developing countries and for vulnerable categories of consumers (OECD, 2020a).

- adapting the retail sector to new food consumption trends - transferring the volume of food consumed away from home to the retail sector is not easy, involving both logistical challenges, but also adjusting to home consumption patterns that are different from those previously practiced away from home (OECD, 2020b); in Romania, the short food chain has been replaced by direct partnerships - direct trade relations between retailers and agri-food producers for at least 12 months and a waiver of the retailer's obligation to supply the short food chain with at least $51 \%$ of the volume of goods on the shelf in the case of products such as dairies, bakery products, eggs, meat, vegetables, fruits, honey - republished Law no. 321 of October 15, 2009 (Romanian Parlament, 2020). 
- changes in the structure of retail products - sales of frozen and packaged food have increased dramatically. After a spectacular initial increase (of up to $63 \%$ in France and $56 \%$ in Germany), the retail demand for frozen or packaged products remained about $15-20 \%$ higher than usual (Boston Consulting Group; IRi Growth delivered, 2020).

- frequency of food purchases decreased significantly during the pandemic compared to the previous period - some people partially replacing fresh food with frozen and canned food.

- declining incomes due to the pandemic had different effects on the changes in food consumption: in Slovenia, there was a decrease in the consumption of fruits and vegetables, ready meals, alcoholic beverages and an increase in the consumption of bread. Opposite trends were observed in other countries: in Denmark, the consumption of sweet snacks and alcoholic beverages increased; in Germany, the consumption of frozen foods and ready meals has increased (Janssen, et al., 2021).

- $\quad$ changes in the availability of food supply in stores delayed deliveries due to restrictions imposed led to reduced availability or even unavailability on the shelf of certain categories of products; in the United States, studies regarding the behavior and consumption of groceries during the first wave of the pandemic caused by COVID-19 show that, due to depletion of stocks in stores, consumers were buying food that was available on the shelf

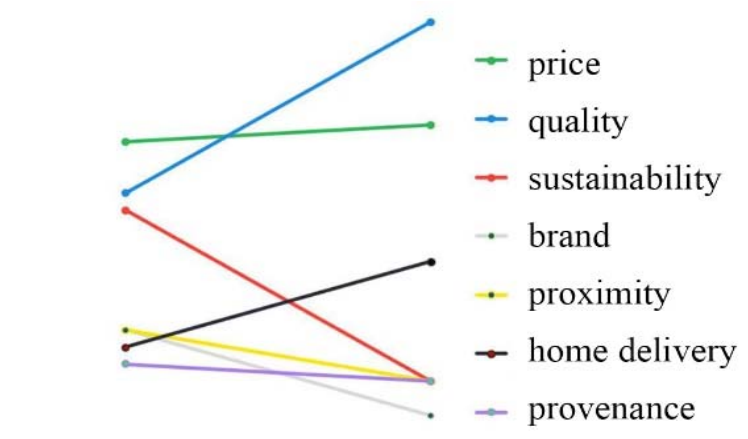

Before Covid-19 After Covid-19

Figure no. 3. Acquisition criteria before and after the beginning of the pandemic in Romania Source: Carstoiu, Ernst and Young 2020 (Chenarides, et al., 2021). In

Romania, retailers have tried to adapt by placing additional orders, streamlining stocks of sensitive products, changing internal flows and those made with suppliers, accepting batches of products with shorter shelf life, increasing the supply of local food. The ability to respond to major changes in demand is conditioned by the nature of the products, for example vegetables and fruits have a low level of stocks relative to the sales volume, while commodities have significantly higher stocks (Competition Council Romania, 2020).

- the increasingly important role of food quality in the consumption decision - according to a Ernst and Young study, considerable changes were found in terms of purchasing criteria in Romania, as seen in Figure no. 3, quality becoming the main factor taken into account, with the largest increase in importance during the pandemic, of $66 \%$, followed by price as a level of importance. The possibility of home delivery also registered a significant increase, with more than a third of study respondents preferring to order food online with home delivery. Criteria such as sustainability, brand, proximity and provenance have decreased in importance in the food purchasing decision (Carstoiu, 2020).

Summarizing, we can say that the changes in food consumption registered on the Romanian market are, with small differences, in line with the trends manifested on the global market, as shown in Figure no. 4. 


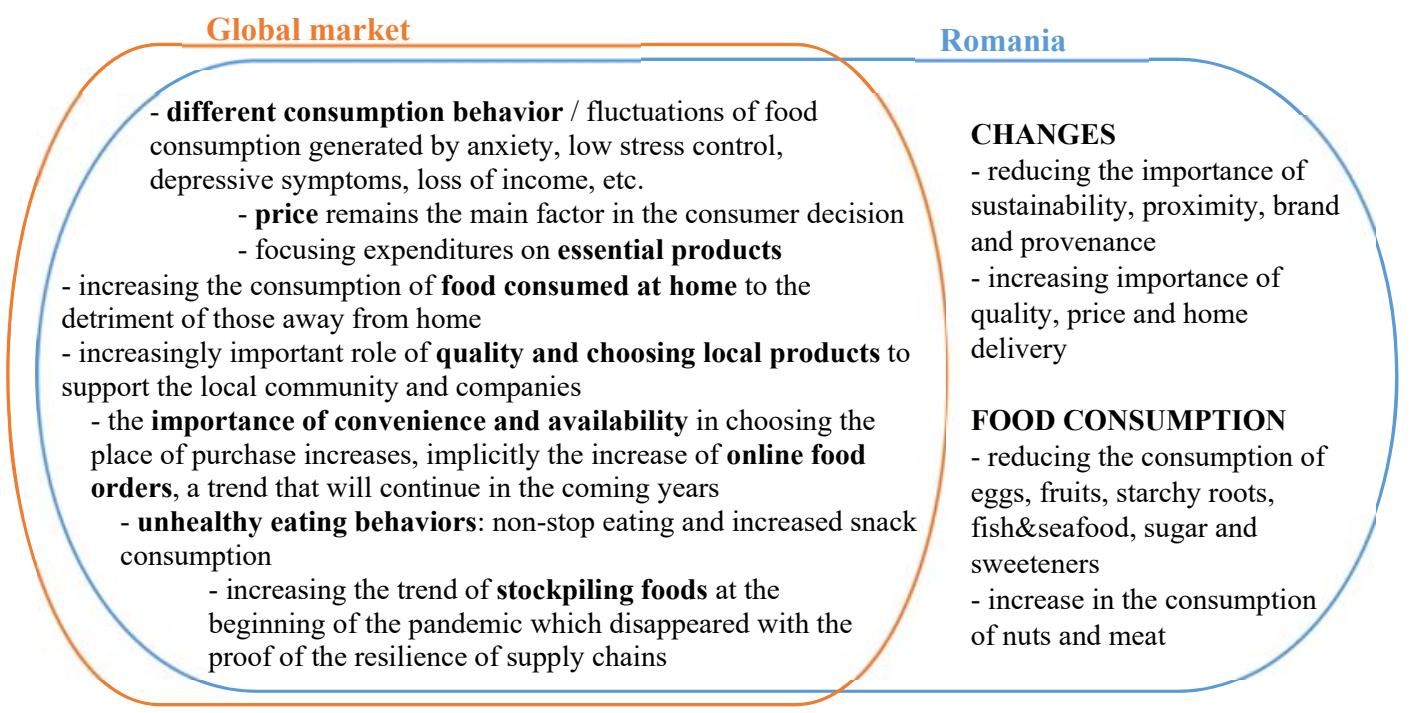

Figure no. 4. Summary of changes in food consumption preferences generated by Covid-19 Source: Own representation based on literature review and secondary data analysis

\section{Conclusions}

The analysis of the changes generated by Covid-19 on food consumption preferences in Romania highlighted an increased interest towards essential foods and implicitly a higher increase in Fresh Food consumption compared to Packaged Food, similar to the global trend. An increased importance placed on food quality and delivery methods can also be observed, with the convenience of online orders becoming an important factor in the purchasing decision. At the same time, there was an increase in the interest in consuming local products and the intention to support the community and the companies operating locally. For each type of food, the level of consumption before and after the beginning of the pandemic was compared and, in the case of Romania, there was an increase in consumption of vegetables, meat, nuts, pulses and a decrease in consumption of starchy roots, fruits, sugar and sweeteners, eggs, fish and seafood. What is interesting to note is that much of the current changes in consumer behavior are predicted to continue in the future.

Eating patterns, influenced by pandemic factors, are based on the three components of human-food interaction: (1) personal component - based on elements characteristic of the individual's physical, emotional, aesthetic, economic and social environment, factors related to time, income level, skill, information and education; (2) the national component - which reflects both food culture and education at the national level with consumption habits and food traditions, as well as the demand-supply relationship; (3) the international component - through the effects induced by globalization and global economic interests. The realities thus identified during the pandemic must be wisely exploited by producers and retailers to meet consumer demand, to design effective strategies based on innovation, design and improving product quality. The pandemic generated by COVID-19 can lead to the redesign of a flexible and resilient agri-food system, facilitating the transition to more equitable partnerships between farmers, producers, retailers and consumers, to more sustainable production, supply and consumption patterns.

In what regards the limitations of this research, we acknowledge that, despite the low occurrence of such an impacting and disruptive worldwide phenomenon like a pandemic, the analysis stands as proof of how the consumer's eating behavior can be influenced both in the short and long term even if the factor causing the disturbance is not directly related to the food sector. In this also resides the replicability of the analysis for various other events. Future research can revisit the analysis by comparing the estimated figures with the future reality. 
References

Borsellino, V., Kaliji, S.A. and Schimmenti, E., 2020. COVID-19 Drives Consumer Behaviour and Agro-Food Markets towards Healthier and More Sustainable Patterns. Sustainability, 12(20), Article number: 8366.

Boston Consulting Group; IRi Growth delivered, 2020. Consumer Spending Tracker for Measured Channels. [pdf] Available at: <https://www.iriworldwide.com/IRI/media/Library/2020-05-15-IRIBCG-COVID-Global-Consumer-Spend-Tracker.pdf> [Accessed 10 March 2021].

Business Wire, 2021. Global Online Food Delivery Services Market (2020 to 2030) - COVID-19 Growth and Change, [online] Available at: $<$ https:/www.businesswire.com/news/home/20200511005687/en/ Global-Online-Food-DeliveryServices-Market-2020-to-2030---COVID-19-Growth-and-Change---ResearchAndMarkets.com> [Accessed 2 February 2021].

Carstoiu, C., 2020. How did COVID-19 shape the behavior of Romanian consumers? [online] EY Romania. Available at: <https://www.ey.com/ro_ro/covid-19/comportamentul-consumatoruluiroman-in-contextul-covid-19-> [Accessed 23 February 2021].

Chenarides, L., Grebitus, C., Lusk, J.L. and Printezis, I., 2021. Food consumption behavior during the COVID-19 pandemic. Agribusiness, 37(1), pp.44-81.

Competition Council Romania, 2020. Raport - Evoluția concurenței în sectoare cheie 2020. [pdf] Available at: <http://www.consiliulconcurentei.ro/wp-content/uploads/2020/11/Raport-SectoareCheie-2020.pdf $>$ [Accessed 23 February 2021].

Euromonitor International, 2021. Fresh Food vs Packaged Food Market Sizes Historical/Forecast, [online] Available at: <https:/www-portal-euromonitor-com.am.enformation.ro/portal/magazine/homemain $>$ [Accessed 10 February 2021].

Janssen, M., Chang, B.P.I., Hristov, H., Pravst, I., Profeta, A. and Millard, J., 2021. Changes in Food Consumption During the COVID-19 Pandemic: Analysis of Consumer Survey Data From the First Lockdown Period in Denmark, Germany, and Slovenia. Frontiers in Nutrition, [online] 8. Available at: $<$ https://www.frontiersin.org/articles/10.3389/fnut.2021.635859/full>.

McKINSEY and Company, 2020. Consumer sentiment and behavior continue to reflect the uncertainty of the COVID-19 crisis. [online] Available at: <https://www.mckinsey.com/businessfunctions/marketing-and-sales/our-insights/a-global-view-of-how-consumer-behavior-ischanging-amid-covid-19\#> [Accessed 11 March 2021].

OECD, 2020a. Food Supply Chains and COVID-19: Impacts and Policy Lessons, [online] Available at: $\quad<$ https://www.oecd.org/coronavirus/policy-responses/food-supply-chains-and-covid-19impacts-and-policy-lessons-71b57aea/https:/www.oecd.org/coronavirus/policy-responses/foodsupply-chains-and-covid-19-impacts-and-policy-lessons-71b57aea/> [Accessed 5 February 2021].

OECD, 2020b. Preliminary Report: Evaluation of the Impact of the Coronavirus (COVID-19) on Fruit and Vegetables Trade. [pdf] Available at: <https://www.oecd.org/agriculture/fruitvegetables/oecd-covid-19-impact-on-fruit-and-vegetables-trade.pdf $>$ [Accessed 14 January 2021].

OpenTable, 2020. The restaurant industry in recovery, [online] Available at: $<$ https://www.opentable.com/ state-of-industry> [Accessed 6 Feb. 2021].

PricewaterhouseCoopers, 2021. Evolving priorities: COVID-19 rapidly reshapes consumer behavior, [online] Available at: $<$ https://www.pwc.com/us/en/industries/consumer-markets/library/covid-19consumer-behavior-survey.html $>$ [Accessed 4 March 2021].

Research and Markets, 2021a. Europe Online Food Delivery (New Delivery Players and Aggregators) Market Report 2021-2026: Analysis and Forecast by User, Country, and Company, [online] Available at: <https://www.globenewswire.com/news-release/2021/03/09/2189252/0/en/EuropeOnline-Food-Delivery-New-Delivery-Players-Aggregators-Market-Report-2021-2026-AnalysisForecast-by-User-Country-Company.html> [Accessed 10 March 2021].

Research and Markets, 2021b. Europe Online Food Delivery Market and User, Country, Company Analysis and Forecast, [online] Available at: < https://www.researchandmarkets.com/reports/5265150/europe-online-food-delivery-market-anduser?utm_source=GNOMandutm_medium $=$ PressReleaseandutm 


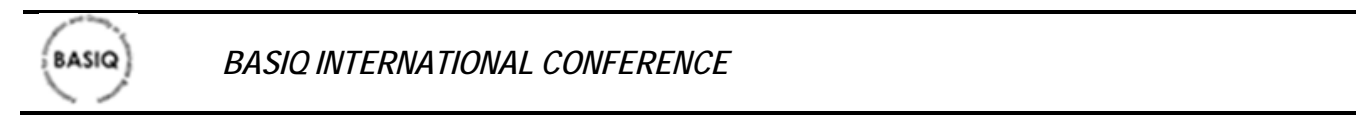

code $=$ nf5w9sandutm_campaign $=1509682+-+$ Europe + Online + Food + Delivery $+($ New + Delivery + Players+\%26+Aggregators)+Market+Report+> [Accessed 3 March 2021].

Romanian Parlament, 2020. Law no. 28 of March 27, 2020 for the amendment and completion of Law no. 321/2009 on the marketing of food products, [online] Available at: $<$ http://legislatie.just.ro/Public/DetaliiDocument/224566> [Accessed 7 February 2021].

Sandi Wachyuni, S. and Wiweka, K., 2020. The changes in food consumption behavior: A rapid observational study of Covid-19 pandemic. International Journal of Management, Innovation and Entrepreneurial Research, 6(2), pp.77-87.

Simone, M., Emery, R.L., Hazzard, V.M., Eisenberg, M.E., Larson, N. and Neumark-Sztainer, D., 2021. Disordered eating in a population-based sample of young adults during the COVID-19 outbreak. International Journal of Eating Disorders, pp.1-13.

UNESCO, 2001. UNESCO Universal Declaration on Cultural Diversity, [online] Available at: $<$ https://unesdoc.unesco.org/ark:/48223/pf0000124687.page=67> [Accessed 7 February 2021]. 